\title{
RESISTANCE TO SMALL DOSES OF INSULIN IN VARIOUS CLINICAL CONDITIONS ${ }^{1}$
}

\author{
By NORMAN S. OLSEN AND JOHN A. NUETZEL \\ (From the Hypertension Division, Department of Internal Medicine, and the Oscar Johnson \\ Institute, Washington Unizersity School of Medicine, and the Barnes Hospital, \\ St. Louis, Missouri)
}

(Submitted for publication August 1, 1949; accepted, March 13, 1950)

In a number of clinical conditions the response of the level of blood sugar to a given dosage of insulin is less than that obtained in normal individuals. This phenomenon is commonly termed insulin resistance. Soon after the discovery of insulin numerous investigators described resistance in certain cases of diabetes mellitus. Radoslav (1) in 1924 administered known amounts of insulin to fasting individuals suffering from diabetes mellitus and pointed out that diabetics, without known complications, might be insulin resistant, insulin sensitive, or insulin hypersensitive. The early investigations on this subject were comprehensively reviewed in 1933 (2) ; since that time, there have been numerous reports describing insulin resistance in diabetes. Although the resistance has usually been attributed to various disorders complicating the diabetic state, certain cases exhibiting this phenomenon in marked degree have been unexplained (3). In 1941 Fraser, Albright, and Smith (4) demonstrated variations in response to the intravenous administration of $1 / 10$ of a unit of insulin per $\mathrm{kg}$. of body weight in a number of endocrine disorders. The dosage recommended by these authors has been employed by other investigators to show insulin resistance in schizophrenics (5), pellagrins (6), and in a small group of hypertensives (7). Kronenberg and McCulloch (8), employing a much smaller dose, 1/40 unit per kg.. demonstrated increased tolerance to insulin in oneirophrenics and in several cases of acromegaly and malignant hypertension. The present investigation explored this phenomenon in 99 patients suffering from hypertension and from other disease conditions, and in 25 normal subjects. The smaller dose of Kronenberg and

1 This work was supported by a grant-in-aid from the National Heart Institute, U. S Public Health Service, and one from Eli Lilly and Company. It was presented in part at the 33rd annual meeting of the Federated Societies, Detroit, April 18, 1949.
McCulloch was used in an attempt to increase the sensitivity of the test, and make possible the identification of submaximal responses that may have been masked by the larger doses recommended by previous workers.

\section{METHOD}

All subjects, except controls, were hospitalized and were receiving a normal hospital diet of high carbohydrate content. In no case was there a recent episode of anorexia or voluntary starvation, although some patients with neoplastic diseases had lost considerable weight. Subjects were fasted for 12 hours preceding the test. After collection of a sample of venous blood, 1/40 unit per $\mathrm{kg}$. of body weight of crystalline insulin (Lilly) was injected intravenously, dosage being calculated on the basis of actual rather than ideal weight. The same lot of insulin was used throughout the series. To avoid small errors in dosage the insulin was diluted with physiological saline so that $1 \mathrm{ml}$. contained 1 unit. Venous blood was obtained at exactly 15,30 and 60 minutes following injection. All blood samples were refrigerated until completion of the test and then were immediately analyzed for glucose by the microcolorimetric method of Nelson (9).

\section{RESULTS}

The effect of various dietary regimens on the response to the test dose of insulin has been investigated. ${ }^{2}$ Three diets have been studied in the same normal subjects: a normal or hospital diet of high carbohydrate content, a low carbohydrate diet, and a low caloric diet. Table I shows the dietary composition, the mean fasting value of blood sugar and the mean per cent fall from the fasting level at the various time intervals. The mean per cent fall has been used, rather than the actual blood sugar value, in order to nullify variations in fasting values. Seven normal subjects were used for this study. In order to determine the reliability of single tests, three separate experi-

2 The authors are indebted to Dr. Edward F. Edinger, Department of Medicine, and Miss Henrietta Becker, Department of Dietetics, for their assistance in this study. 
TABLE I

Effect of diet on response to intravenous insulin

\begin{tabular}{|c|c|c|c|c|c|c|c|c|}
\hline \multicolumn{5}{|c|}{ Diet } & \multirow{2}{*}{$\begin{array}{c}\text { Mean fasting } \\
\text { value of blood sugar }\end{array}$} & \multicolumn{3}{|c|}{ Mean \% fall from fasting value } \\
\hline Type & $\begin{array}{c}\text { Total } \\
\text { calories }\end{array}$ & Protein & Fat & $\mathrm{CHO}$ & & 15 min. & $30 \mathrm{~min}$. & $60 \mathrm{~min}$. \\
\hline \multirow[t]{2}{*}{$\begin{array}{l}\text { Normal-Hospital } \\
\text { Low CHO } \\
\text { Low Calorie }\end{array}$} & \multirow[t]{2}{*}{$\begin{array}{r}2030 \\
1520 \\
750\end{array}$} & \multirow[t]{2}{*}{$\begin{array}{r}\mathrm{gm} . \\
70 \\
120 \\
50\end{array}$} & \multirow[t]{2}{*}{$\begin{array}{r}g m . \\
100 \\
80 \\
60\end{array}$} & \multirow[t]{2}{*}{$\begin{array}{r}g m . \\
250 \\
30 \\
40\end{array}$} & $\begin{array}{c}\text { mg. \% } \\
80.1 \\
76.3 \\
75.0\end{array}$ & $\begin{array}{c}\% \\
34.6 \\
28.1 \\
29.4\end{array}$ & $\begin{array}{c}\% \\
43.9 \\
42.7 \\
43.9\end{array}$ & $\begin{array}{c}\% \\
10.7 \\
10.6 \\
11.3\end{array}$ \\
\hline & & & & & "F" Value* & 2.87 & 0.22 & 0.08 \\
\hline
\end{tabular}

* On applying the analysis of variance to the data the following " $F$ " values must be equalled or exceeded to show significant variation between diets: $1 \%$ significance " $F "=6.93 ; 5 \%$ significance " $F "=3.58$.

ments on a normal diet were run on each subject. No significant variation in the response to the intravenous injection of $1 / 40$ unit of insulin per $\mathrm{kg}$. body weight was found in any of the subjects. Therefore only one test was subsequently run on each of the other two diets. The subjects were placed on the separate diets for a period of three days and the test performed on the following day. Using analysis of variance (10) it was found that there was no variation in the response to the test dose of insulin in subjects on the three diets up to the 5 per cent level of significance.

In Table II are shown the results obtained on normal and hospitalized subjects. Twenty-five normal subjects were selected from the laboratory personnel and used as a control "no-disease" group; the mean per cent fall was 34.5 per cent in 15 minutes, 39.0 per cent in 30 minutes, and 10.1 per cent in 60 minutes. Considerable variation was found, the maximum fall from the basal level varying between 24 and 56 per cent. In no case was this fall less than 24 per cent. When tests were repeated two or three times on each of eight normal subjects a marked consistency of response for each individual was found. Results on 99 hospital patients have been divided into distinct groups according to type of disease. Using Fisher's method for small samples (11), analysis re-

TABLE II

The response of blood glucose to intravenous insulin

(1/40 unit per kg.)

\begin{tabular}{|c|c|c|c|c|c|}
\hline \multirow{2}{*}{ Group } & \multirow{2}{*}{ No. patients } & \multirow{2}{*}{$\begin{array}{c}\text { Mean } \\
\text { fasting value of } \\
\text { blood sugar* }\end{array}$} & \multicolumn{3}{|c|}{ Mean \% fall from fasting value } \\
\hline & & & $15 \mathrm{~min}$. & $30 \mathrm{~min}$. & $60 \mathrm{~min}$. \\
\hline $\begin{array}{l}\text { No disease } \\
\text { Essential hypertension } \\
\quad \text { Neurogenic } \\
\quad \text { Endocrine } \\
\text { Vascular } \\
\text { Malignant hypertension } \\
\text { Collagen } \\
\text { Neoplastic } \\
\text { Hepatic } \\
\text { Infection } \\
\quad \text { Severe } \\
\text { Low grade }\end{array}$ & $\begin{array}{r}25 \\
38 \\
20 \\
10 \\
8 \\
11 \\
10 \\
15 \\
6 \\
\\
8\end{array}$ & $\begin{array}{l}m g . \% \\
84.6 \\
84.1 \\
83.2 \\
85.5 \\
84.0 \\
86.9 \\
82.1 \\
84.9 \\
84.3 \\
\\
95.8 \\
84.1\end{array}$ & $\begin{array}{c}\% \\
34.5(1.9) \\
29.7(2.4) \\
30.3(4.0) \\
34.9(3.8) \\
22.0(3.7) \\
\frac{10.0(2.2)}{\frac{15.7(2.8)}{8.5(3.0)}} \\
\frac{8.0(2.0)}{26.7(2.8)}\end{array}$ & $\begin{array}{c}\% \\
39.0(2.9) \\
41.6(2.3) \\
41.5(3.2) \\
47.0(4.1) \\
35.1(4.1) \\
\frac{15.9(2.3)}{22.4(3.1)} \\
\frac{13.8(3.7)}{13.7(2.1)} \\
\frac{12.3(3.7)}{32.5(2.4)}\end{array}$ & $\begin{array}{c}\% \\
10.1(1.6) \\
11.9(1.1) \\
12.3(2.2) \\
13.7(2.7) \\
9.0(3.8) \\
4.9(2.7) \\
2.3(3.9) \\
3.4(2.4) \\
0.0(2.7) \\
6.5(2.5) \\
10.5(2.7)\end{array}$ \\
\hline
\end{tabular}

* After a 12 hour fast a sample of venous blood was obtained from the patient. Samples of venous blood were withdrawn 15, 30,60 minutes after intravenous injection of 1/40 unit of insulin per $\mathrm{kg}$. Blood sugar was determined in the aliquots by the micro-method of Nelson (9). The numbers in parentheses following the mean per cent falls are the standard errors. The probability that the difference of the underscored values from normal is due to chance is less than onetenth of 1 per cent. 
vealed that the probability of the difference in the underscored values from the normal being due to chance was less than one-tenth of 1 per cent.

1. Hypertension. Patients were classified as having "essential" or malignant hypertension. The latter group was characterized on the basis of a rapidly progressive course, grade four retinopathy, evidence of renal damage, and a markedly elevated diastolic blood pressure. No significant difference in response to insulin was found to exist between "essential" hypertension and the normal group. However, malignant hypertensive patients were all definitely insulin resistant, and, in general, the degree paralleled the severity of the disease. A few individuals in the "essential" hypertensive group were also resistant, but in all of them there existed either severe psychoneuroses or other complications such as apoplectic stroke, heart failure, or pulmonary embolism.

Since it is generally recognized that essential hypertension probably includes a number of subgroups which may differ in regard to etiology and response to treatment, patients were further classified according to the types suggested by Schroeder and Steele (12). The "endocrine" type was made up for the most part of obese females with "pseudo-Cushing's" syndrome (13). Among other findings sweat sodium was low, fat distribution was central, white striae were present over the abdomen, thighs, and breasts, and the elevated blood pressures usually responded well to salt restriction. The neurogenic type comprised the majority and were characterized by the presence of a labile blood pressure, minimal vascular disease, a benign course, and associated emotional disturbances. These patients were usually found to give a positive response to the intradermal histamine test (14). The vascular group was composed of patients whose elevation of blood pressure was associated with arteriosclerosis; they tended to have wide pulse pressures and were in an older age group. Patients in the three aforementioned categories showed slight but statistically insignificant variations from normal in their responses to insulin. Patients with chronic glomerulonephritis and hypertension varied in their responses but seemed to be insulin resistant only during the active phase of their nephritis; there were, however, too few (six) for definite conclusions to be made.
2. Other diseases. A group of collagen disease was made up of patients with rheumatic fever, rheumatoid arthritis, scleroderma and acute disseminated lupus erythematosus. Other groups included neoplastic diseases (carcinoma, Hodgkin's disease, and lymphosarcoma), hepatic and infectious diseases. In each of these groups significant resistance to the action of insulin was found. Patients with severe infections, hepatic and neoplastic diseases were the most resistant. Only in low-grade infections was there no significant change, and only in severe infections was the fasting value of blood sugar appreciably elevated (mean value, $95.8 \mathrm{mg}$. per cent compared to 84.6 mg. per cent in normal individuals).

In general patients showed increasing resistance with increasing severity of disease (Table III).

Comparison of severity of disease state and response to
intravenous insulin*

* Notations same as in Table II.

In a number of endocrine disturbances (four patients with thyrotoxicosis and one each with acromegaly, Cushing's syndrome, obesity and Albright's syndrome) the degree of resistance demonstrated was in good agreement with that previously reported using $1 / 10$ of a unit per $\mathrm{kg}$. of body weight.

\section{DISCUSSION}

To evaluate changes in the level of blood sugar produced by the intravenous administration of insulin three factors are of prime importance: the effect of the nutritional state, the quantity of insulin, and the time of blood sampling. The nutritional status of the subject is well known to have 
a profound effect on the glucose tolerance test and some work has been done demonstrating its effect on the insulin tolerance when larger quantities of insulin have been given. In the present study no significant variation has been noted in cases of high and low carbohydrate, and low calorie diets in normal subjects. It is recognized, however, that the results may be open to question due to the short duration of the experimental periods and the utilization of only normal subjects. The use of minimal doses of insulin has a number of advantages. First, it is possible to apply a stress to the subject which is small enough to detect delicate variations in function which may be completely masked by larger doses. Second, the danger of severe hypoglycemia is avoided especially when patients with endocrine disorders are studied. It has been the practice in many clinics to use similar small quantities of insulin in patients suspected of Addison's disease and panhypopituitarism. Third, the small quantity of insulin produces a minimum of trauma and the effect is dissipated in a short time. The optimum time of blood sampling depends in part on the dosage. However, it is generally recognized that the nadir in the blood sugar is reached somewhere between 15 and 30 minutes after injection of moderate amounts of insulin. It was deemed satisfactory to withdraw venous blood exactly 15 and 30 minutes after injection rather than at more frequent or at varying time intervals. The blood sugar value of the 60 minute sample was considered to be the one approaching the fasting level.

Soskin and Levine (15) have outlined the disturbances which may diminish the normal action of insulin as follows:

“1. Poor absorption from subcutaneous tissues.

" 2 . Abnormally rapid destruction of insulin in skin, blood or other tissues.

"3. Overactivity of the physiological antagonists to insulin, particularly the hormones of the anterior pituitary, adrenal cortex and thyroid glands.

"4. Infections, toxemia, and liver disease, i.e., conditions in which the liver does not respond normally to its endocrine regulators.

"5. Unusual antibody formation to insulin or to other proteins present in insulin preparations."
Insulin resistance in endocrine disorders, hepatic disease, and perhaps in infections, can be explained by one or several of these disturbances. Since, however, in every disease of the variety selected some significant degree of rsistance was found one is inclined to consider a single factor as responsible. The site and action of insulin in the body are still so little understood that many factors may play an important role. For example, recent interest has been focussed on a naturally occurring factor, similar to insulin, causing hyperglycemia which might well be said to have an "anti-insulin" action (16). In vitro inhibition of the hexokinase reaction, produced by adrenal cortical extract, has been shown to be reversed by the addition of insulin (17). Furthermore, adrenal corticoids have long been known to increase glyconeogenesis. In patients with Cushing's syndrome the urinary corticoids are elevated and there is an associated resistance to insulin (18). Most recently Conn, Louis, and Johnston (19) have administered adrenocorticotropic hormone to normal subjects and have observed the production of a diabetic state with an increased resistance to endogenous insulin. These results have been confirmed by other workers (20). Therefore, under certain conditions adrenal corticoids may produce resistance to the action of insulin. Selye (21), on the other hand, has pointed out that increased adrenal-cortical activity occurs during the "resistance" stage of the "general adaptation syndrome." It is beyond the scope of this paper to discuss this theory but there is good evidence that the adrenal cortex increases in size in response to stress and may secrete more hormones, as has been demonstrated after operations (22), pneumonia, cold and other stresses $(18,23)$. It is possible that the present findings are best explained on this basis. Thus, the disease states studied may be considered as non-specific stresses acting on the body to produce, among other things, increased adrenal cortical activity. In essential hypertension the stress may not be great enough to cause a degree of resistance measurable by these methods, or regulating mechanisms may compensate for this particular reaction until a malignant phase is reached. 


\section{SUM MARY}

1. An intravenous insulin tolerance test employing $1 / 40$ unit per $\mathrm{kg}$. of body weight has been used in 25 normal subjects, 49 hypertensive patients, and in 50 patients suffering from other diseases.

2. The response of blood sugar to intravenous insulin in patients with essential hypertension is not significantly different from that in normal individuals, whereas those with malignant hypertension are resistant to a statistically significant degree.

3. Resistance to insulin was found in collagen, neoplastic, hepatic and infectious diseases as well as in certain endocrine disorders.

4. The hypothesis that insulin resistance may be due to increased adrenal cortical activity resulting from a reaction to stress is discussed.

\section{ACKNOWLEDGMENTS}

The technical assistance of Misses Helen L. Hilderman, A.B., Edna Menhard, B.S., and Sallie Wood, R.N., is gratefully acknowledged. The authors wish to express sincere appreciation to Dr. Henry A. Schroeder for advice and criticism.

\section{BIBLIOGRAPHY}

1. Radoslav, C. S., Uber die Wirkung des Insulins auf den Blutzucker beim Menschen. Wein. Arch. f. inn. Med., 1924, 8, 395.

2. MacBryde, C. M., Insulin resistance in diabetes mellitus. Arch. Int. Med., 1933, 52, 932.

3. Glen, A., and Eaton, J. C., Insulin antagonism. Quart. J. Med., 1938, 7, 271.

4. Fraser, R., Albright, F., and Smith, P. H., The value of the glucose tolerance, the insulin tolerance and the glucose-insulin tolerance test in the diagnosis of endocrinologic disorders of glucose metabolism. J. Clin. Endocrinol., 1941, 1, 297.

5. Freeman, H., Looney, J. M., Hoskins, R. G., and Dyer, C. G., Results of insulin and epinephrine tolerance tests in schizophrenic patients and in normal subjects. Arch. Neurol. \& Psychiat., 1943, 49, 195.

6. Gillman, T., Gillman, J., and Mandelstam, J., Studies of carbohydrate metabolism in South African Negro pellagrins. II. Insulin-adrenalin tolerance tests. Federation Proc., 1947, 6, 111.

7. deTakats, G., and Lasner, J., The insulin tolerance of the hypertensive patient. J. Lab. \& Clin. Med., 1948, 33, 1487.
8. Kronenberg, G. J., and McCulloch, W. S., A brief insulin tolerance test. Proc. Soc. Exper. Biol. \& Med., 1947, 64, 492.

9. Nelson, N., A photometric adaptation of the Somogyi method for the determination of glucose. J. Biol. Chem., 1944, 153, 375.

10. Snedecor, G. W., Statistical Method Applied to Experiments in Agriculture and Biology. The Collegiate Press, Ames, Iowa, 1946.

11. Fisher, R. A., Statistical Methods for Research Workers. Oliver \& Boyd, London, 1941, 8th Ed.

12. Schroeder, H. A., and Steele, J. M., Studies on "essential" hypertension. I. Classification. Arch. Int. Med., 1939, 64, 927.

13. Schroeder, H. A., Low salt diets and arterial hypertension. Am. J. Med., 1948, 4, 578.

14. Schroeder, H. A., and Goldman, M. L., Test for the presence of the "hypertensive diencephalic syndrome" using histamine. Am. J. Med., 1949, 6, 162.

15. Soskin, S., and Levine, R., Carbohydrate Metabolism. Correlation of Physiological, Biochemical and Clinical Aspects. Univ. of Chicago Press, Chicago, 1946.

16. Olsen, N. S., and Klein, J. R., Hyperglycemia produced by certain insulin preparations. Proc. Soc. Exper. Biol. \& Med., 1947, 66, 86.

17. Colowick, S. P., Cori, G. T., and Slein, M. W., The effect of adrenal cortex and anterior pituitary extracts and insulin on the hexokinase reaction. J. Biol. Chem., 1947, 168, 583.

18. Albright, F., Cushing's Syndrome. Its pathological physiology, its relationship to the adreno-genital syndrome and its connection with the problem of the reaction of the body to injurious agents ("alarm reaction" of Selye). Harvey Lect., 1942$43,38,123$.

19. Conn, J. W., Louis, L. H., and Johnston, M. W., Metabolism of uric acid, glutathione and nitrogen and excretion of "11-oxysteroids" and 17-ketosteroids during induction of diabetes in man with pituitary adrenocorticotropic hormone. J. Lab. \& Clin. Med., 1949, 34, 255.

20. Elkinton, J. R., Hunt, A. D., Jr., Godfrey, L., McCrary, W. W., Rogerson, A. G., and Stokes, J., Jr., Effects of pituitary adrenocorticotropic hormone (ACTH) therapy. J.A.M.A., 1949, 141, 1273.

21. Selye, $H$., The alarm reaction and the diseases of adaptation. Ann. Int. Med., 1948, 29, 403.

22. Weil, P., and Browne, J. S. L., The excretion of cortin after surgical operation. Science, 1939, 90, 445.

23. Venning, E. H., and Browne, J. S. L., Excretion of urinary corticoid hormones. Federation Proc., 1945, 4, 108. 